\title{
Uncovered versus covered stent in management of large bowel obstruction due to colorectal malignancy: a systematic review and meta-analysis
}

\author{
Meghavi Mashar $^{1} \cdot$ Ruchir Mashar $^{2} \cdot$ Shahab Hajibandeh $^{3}$
}

Accepted: 6 February 2019 / Published online: 23 March 2019

(C) The Author(s) 2019

\begin{abstract}
Purpose To compare outcomes of uncovered stent and covered stent in management of large bowel obstruction secondary to colorectal malignancy.

Methods We conducted a search of electronic databases identifying studies comparing outcomes of uncovered and covered stents in management of large bowel obstruction secondary to colorectal malignancy. The Cochrane risk-of-bias tool and the Newcastle-Ottawa scale were used to assess the included studies. Random or fixed effects modelling were applied as appropriate to calculate pooled outcome data.

Results One randomised controlled trial (RCT) and nine observational studies, enrolling 753 patients, were identified. Uncovered stent was associated with lower risks of complications (RR $0.5795 \%$ CI $0.44-0.74, P<0.0001$ ), tumour overgrowth (RR 0.29 95\% CI 0.09-0.93, $P=0.04$ ), and stent migration (RR $0.2995 \%$ CI $0.17-0.48, P<0.00001$ ); longer duration of patency (MD $18.4795 \%$ CI 10.46-26.48, $P<0.00001$ ); lower need for stent reinsertion (RR $0.3895 \%$ CI $0.17-0.86, P=0.02$ ); and higher risk of tumour ingrowth (RR $4.5395 \%$ CI 1.92-10.69, $P=0.0008$ ). Rates of technical success (RR $1.0295 \%$ CI $0.99-1.04, P=$ 0.21 ), clinical success (RR $1.0395 \%$ CI $0.98-1.08, P=0.32$ ), perforation (RD $0.0195 \% \mathrm{CI}-0.03-0.02, P=0.65$ ), bleeding (RD $0.0095 \% \mathrm{CI}-0.03-0.03, P=0.98$ ), stool impaction (RR $0.5695 \% \mathrm{CI} 0.12-2.04, P=0.38$ ) and stent obstruction (RR 2.23 95\% CI 0.94-5.34, $P=0.97$ ) were similar.

Conclusions Our results suggest that uncovered stents are superior as indicated by fewer complications, lower rates of stent migration, longer duration of patency and a reduced need for stent reinsertion. The best available evidence is mainly derived from non-randomised studies; there is a need for more RCTs.
\end{abstract}

Keywords Intestinal obstruction $\cdot$ Colorectal cancer $\cdot$ Stent

\section{Introduction}

Large bowel obstruction is the presenting feature in $24 \%[1,2]$ of colorectal carcinoma. Malignant obstruction was conventionally treated by surgical diversion and stoma formation, associated with higher morbidity and mortality as compared

Meghavi Mashar

meghavi.mashar@medsci.ox.ac.uk

1 Oxford University Hospitals NHS Foundation Trust, Oxford, UK

2 Department of General Surgery, Hereford County Hospital, Hereford HR1 2BN, UK

3 Department of General Surgery, North Manchester General Hospital, Manchester M8 5RB, UK to elective treatment [3]. Insertion of self-expanding metal stents (SEMS) can be used as a bridge to surgery for subsequent one-stage resection as well as for palliative purposes in those with irresectable tumours. Insertion is associated with equivalent clinical outcomes, decreased hospital stay, fewer complications and lower mortality [4].

Available stents are uncovered and covered, the latter can vary as fully covered and partially covered. Uncovered stents were traditionally associated with increased rates of stent occlusion, and increased tumour ingrowth and overgrowth [5, 6]. Covered stents were designed to hypothetically reduce the rate of tumour ingrowth. However, this is associated with decreased stent patency as the coating decreases the ability of the stent to anchor to the intestinal wall [7].

Little conclusive clinical evidence exists for whether the hypothetical benefits translate clinically. Hence, we aimed to 
perform a comprehensive systematic review and conduct a meta-analysis of outcomes comparing uncovered stent and covered stent in management of large bowel obstruction secondary to colorectal malignancy.

\section{Methods}

This systematic review was performed according to an agreed predefined protocol and was conducted and presented according to Preferred Reporting Items for Systematic Reviews and Meta-Analyses (PRISMA) statement standards.

\section{Eligibility criteria}

Observational studies and RCTs investigating outcomes of uncovered versus covered SEMS in management of large bowel obstruction secondary to colorectal malignancy were included. The population of interest comprised adults over the age of 18 undergoing SEMS insertion for relief of large bowel obstruction secondary to primary colorectal malignancy or colorectal metastases from other malignancies. The intervention of interest was uncovered SEMS insertion and the comparator, covered SEMS insertion. Studies including cases with large bowel obstruction secondary to extrinsic compression and studies investigating stents for gastric outlet, biliary or small bowel obstruction were excluded.

\section{Outcomes}

The following outcome measures were considered: technical success, clinical success, total complications (early and late), perforation, bleeding, stent migration (total, early and late), tumour ingrowth, tumour overgrowth, stool impaction, stent obstruction, duration of stent patency, and need for stent reinsertion.

\section{Literature search strategy}

Two authors (MM, RM) independently conducted a literature search on the following databases: MEDLINE, EMBASE and CINAHL and the Cochrane Central Register of Controlled Trials (CENTRAL). The final search was conducted on 17 June 2018. Search operators, thesaurus headings and limits in each database were adjusted as necessary; this strategy is outlined in Fig. 1. ClinicalTrials.gov, the World Health Organisation International Clinical Trials Registry and ISRCTN Register were searched for ongoing trials or unpublished studies. References of related reviews were searched for any other relevant studies. Language restrictions were not applied during the literature search.

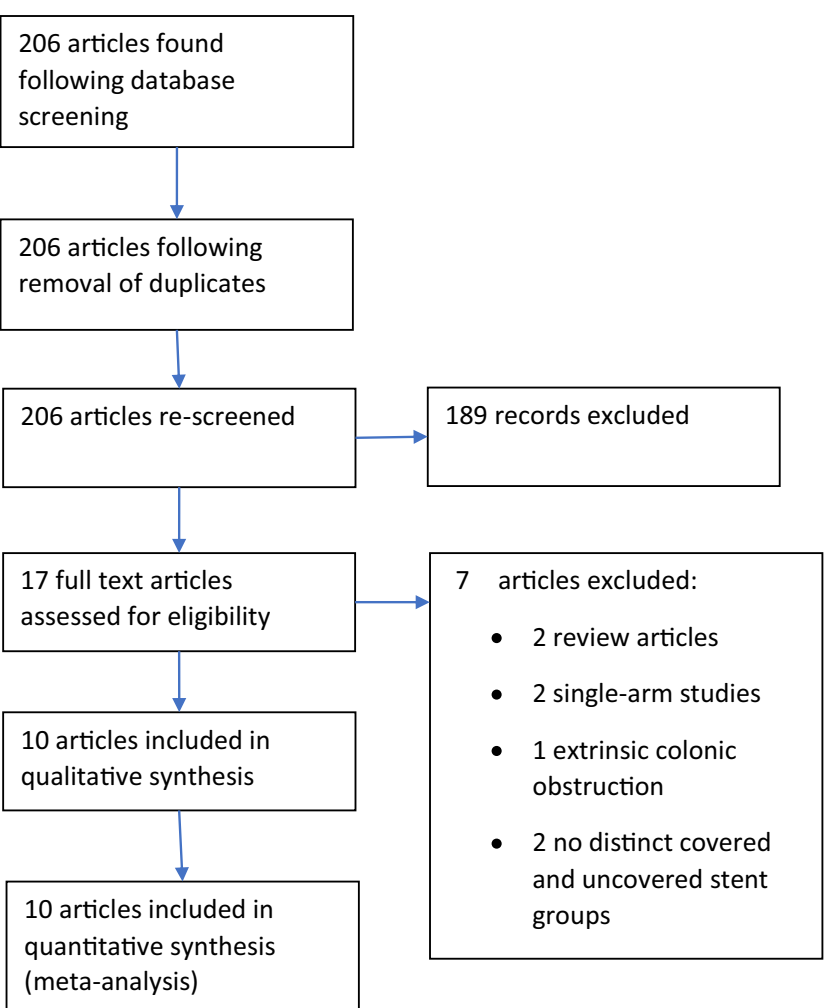

Fig. 1 Study flow diagram

\section{Study selection}

Two authors (MM, RM) independently reviewed titles and abstracts. Subsequently, full texts were retrieved for relevant articles. Eligible studies were selected. In the event of discrepancy, the two authors discussed and a third ( $\mathrm{SH}$ ) was consulted if they could not agree.

\section{Data collection}

An electronic data collection spreadsheet was created, which was piloted and adjusted using random articles. Data collection included study-related information (first author, year of publication, country of origin of the corresponding author, publishing journal, study design, number of participants and their clinical condition), baseline characteristics of the included population (age, gender, purpose for stenting, site of obstruction), characteristics of the SEMS (shape, cover), primary, and secondary outcome data. Two authors independently collected the data (MM, RM). Disagreements were initially discussed. If no resolution could be reached, a third author (SH) was consulted.

\section{Methodological quality and risk of bias assessment}

Two authors independently assessed methodological quality and risk of bias of the articles using the Cochrane tool and 
the Newcastle-Ottawa scale (NOS) for assessing the risk of bias of randomised trials and observational studies, respectively. The Cochrane tool assesses domains including selection bias, performance bias, detection bias, attrition bias, reporting bias and other sources of bias and, for each individual domain, classifies studies into low, unclear and high risk of bias. The NOS uses a star system with a maximum of nine stars to evaluate a study in three domains (eight items): the selection of the study groups, the comparability of the groups and the ascertainment of outcome of interest. For each item of the scale, we judged each study as low risk (one star awarded) or high risk (no star awarded). We determined studies that received a score of nine stars to be of low risk of bias, studies that scored seven or eight stars to be of moderate risk, and those that scored six or less to be of high risk of bias. Disagreements were resolved by discussion between the reviewers. If no agreement could be reached, a third author was consulted. A risk of bias graph was constructed to present the results.

\section{Data synthesis and statistical analyses}

For dichotomous outcome variables, risk ratios (RR) were calculated as the summary measure for uncovered vs covered stents. We planned to calculate the risk difference (RD) when more than a third of the studies had zero events in both groups. For continuous parameters, the mean difference between the covered and uncovered stent groups was calculated. The unit of analysis was individual patient. Any information regarding withdrawals, dropouts and other missing data were recorded. We based our analysis on intention-to-treat data from individual clinical studies. Review Manager 5.3 software was used for data synthesis. Random or fixed effects modelling were applied as appropriate for analyses; random-effect models were used if considerable heterogeneity was found amongst studies. Forest plots with $95 \%$ confidence intervals (CIs) were used to present the results. Cochran's $Q$ test was used to assess inter-study heterogeneity. We calculated $I^{2}$ to quantify inconsistency, and it was interpreted according to the following guide: $0-50 \%$ indicated low heterogeneity, $50-75 \%$ indicated moderate heterogeneity and $75-100 \%$ indicated high heterogeneity. We intended to construct funnel plots and visually assess their symmetry to evaluate publication bias for outcomes reported by at least ten studies.

\section{Sensitivity and subgroup analyses}

To explore potential sources of heterogeneity and assess the robustness of our results, additional analyses were conducted for outcomes reported by at least four studies. We repeated the primary analysis using the random effects and fixed effect model. In addition, we calculated the RR, odds ratio (OR) and RD separately for dichotomous outcomes. We assessed the effect of each study on the overall effect size and heterogeneity by repeating the analysis after removing one study at a time. We planned to perform separate analyses for RCTs with low risk of selection bias in terms of randomisation and allocation concealment to assess the change in direction of the effect size. Moreover, where possible, we aimed to perform subgroup analysis based on shape and type of covered stent (cylindrical shape vs dumbbell shape, fully covered vs partially covered), or purpose for stenting (preoperative decompression vs palliative).

\section{Results}

\section{Results of search}

Literature searching gave rise to 207 studies, of which 10 were eligible [5, 8-16]. These included seven prospective cohort studies, two retrospective cohort studies and one RCT, in total 753 patients. The indication for stenting was preoperative decompression or palliative management in six studies, palliative management only in three studies, preoperative decompression only in one study. Overall, 301 patients underwent covered stent insertion and 452 patients underwent uncovered stent insertion. In terms of the shape of covered stent, three studies used cylindrical-shaped or dumbbell-shaped stents; four studies used cylindrical-shaped stents only; two studies used dumbbell-shaped stents only; one study used dumbbellshaped or bamboo-shaped stents. Length of follow-up period ranged from 2 to 20 months. Nine studies defined technical success as accurate stent placement, and nine defined clinical success as relief of obstruction clinically. The literature search flow chart, baseline characteristics of included studies and baseline characteristics of the included populations are demonstrated in Fig. 1 and Tables 12 , respectively.

\section{Methodological quality}

The summary and results of methodological quality assessment of the one RCT [8] and nine observational studies [5, 9-16] are demonstrated graphically in Fig. 2.

\section{Outcome synthesis}

Technical success Technical success of stent insertion was reported in 8 studies [5, 8-11, 14-16], enrolling 644 patients. There was no significant difference in technical success of stent insertion (RR $1.0295 \%$ CI $0.99-1.04, P=0.21$ ). A low level of inter-study heterogeneity existed $\left(I^{2}=0 \%, P=\right.$ 0.79) (Fig. 3).

Clinical success $C$ linical success of stent insertion was reported in 5 studies $[5,8-10,15]$, enrolling 422 patients. There was no 


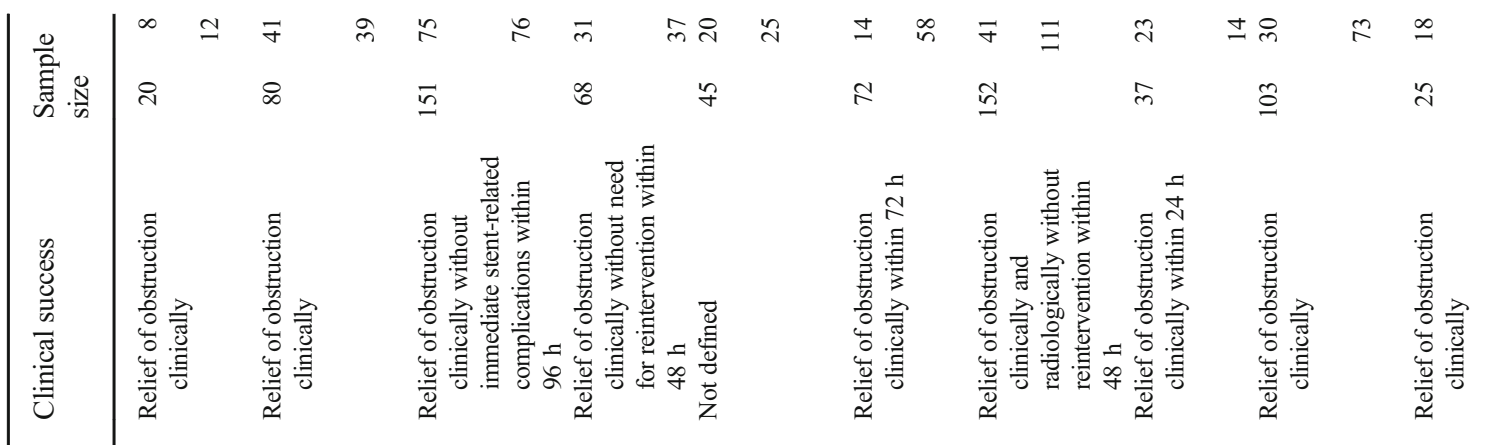

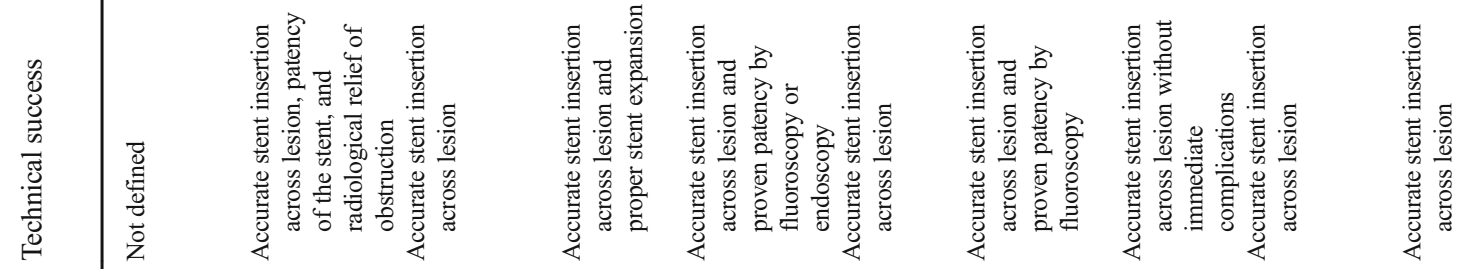

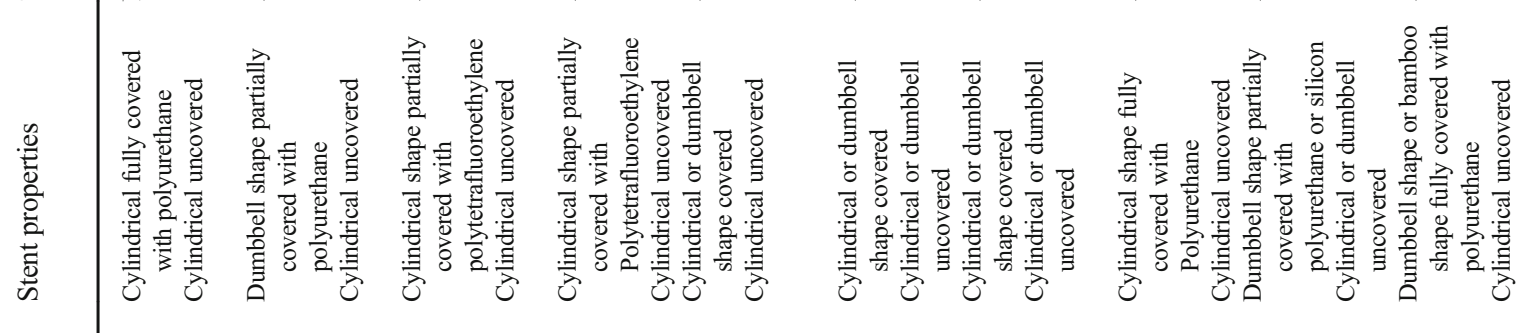

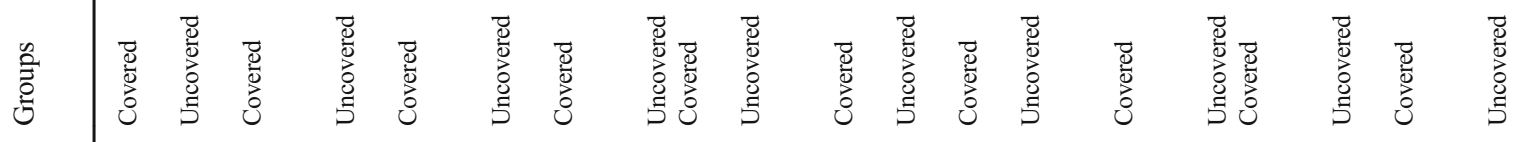

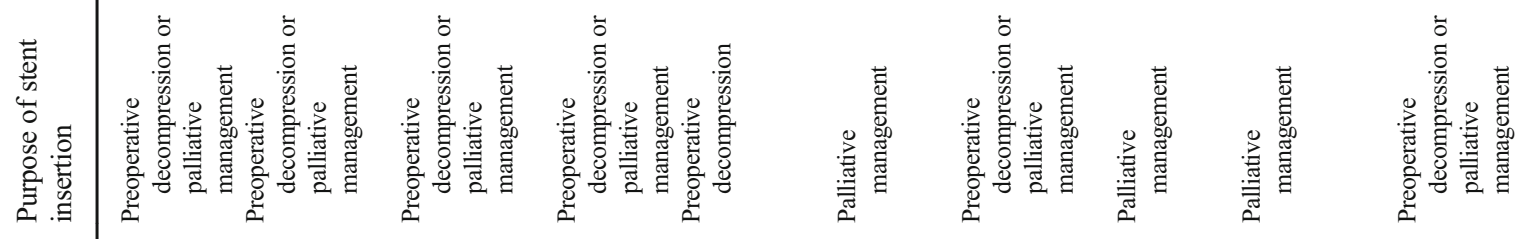

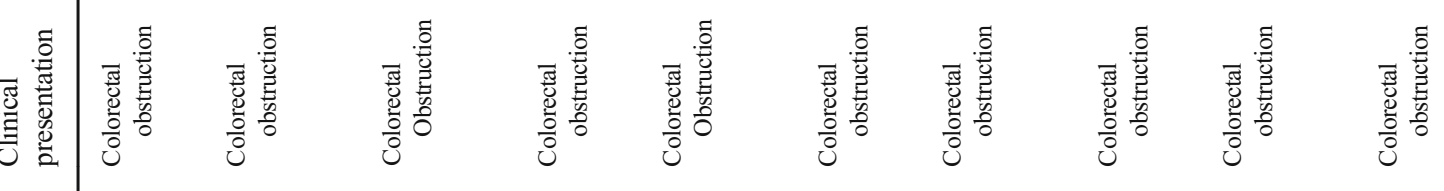

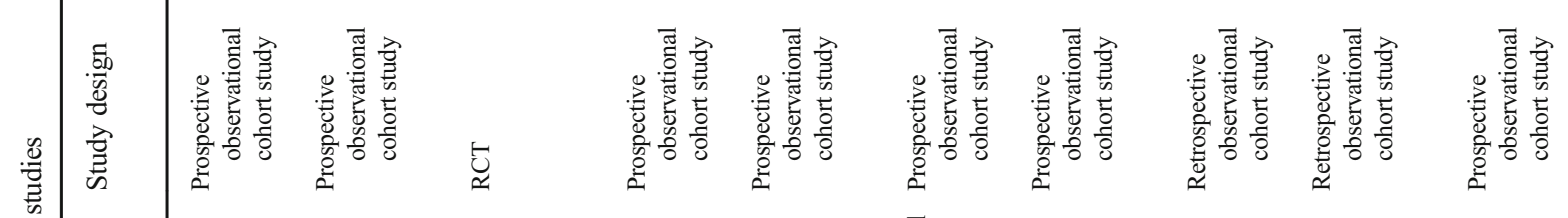

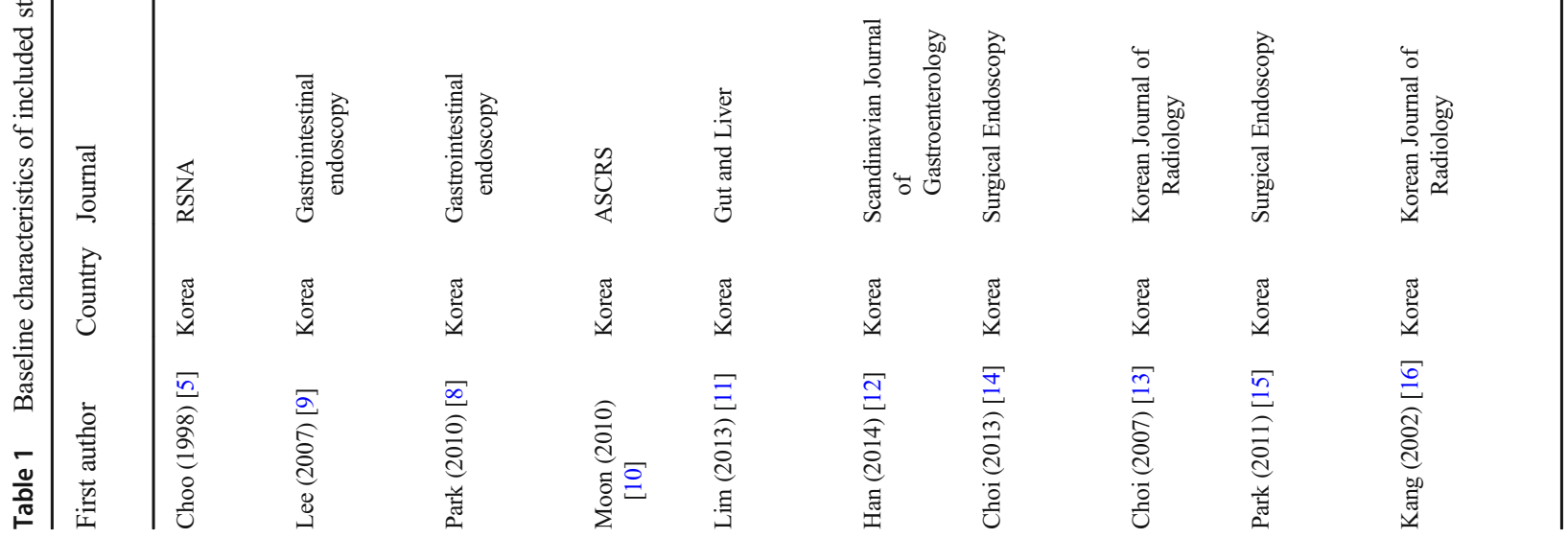




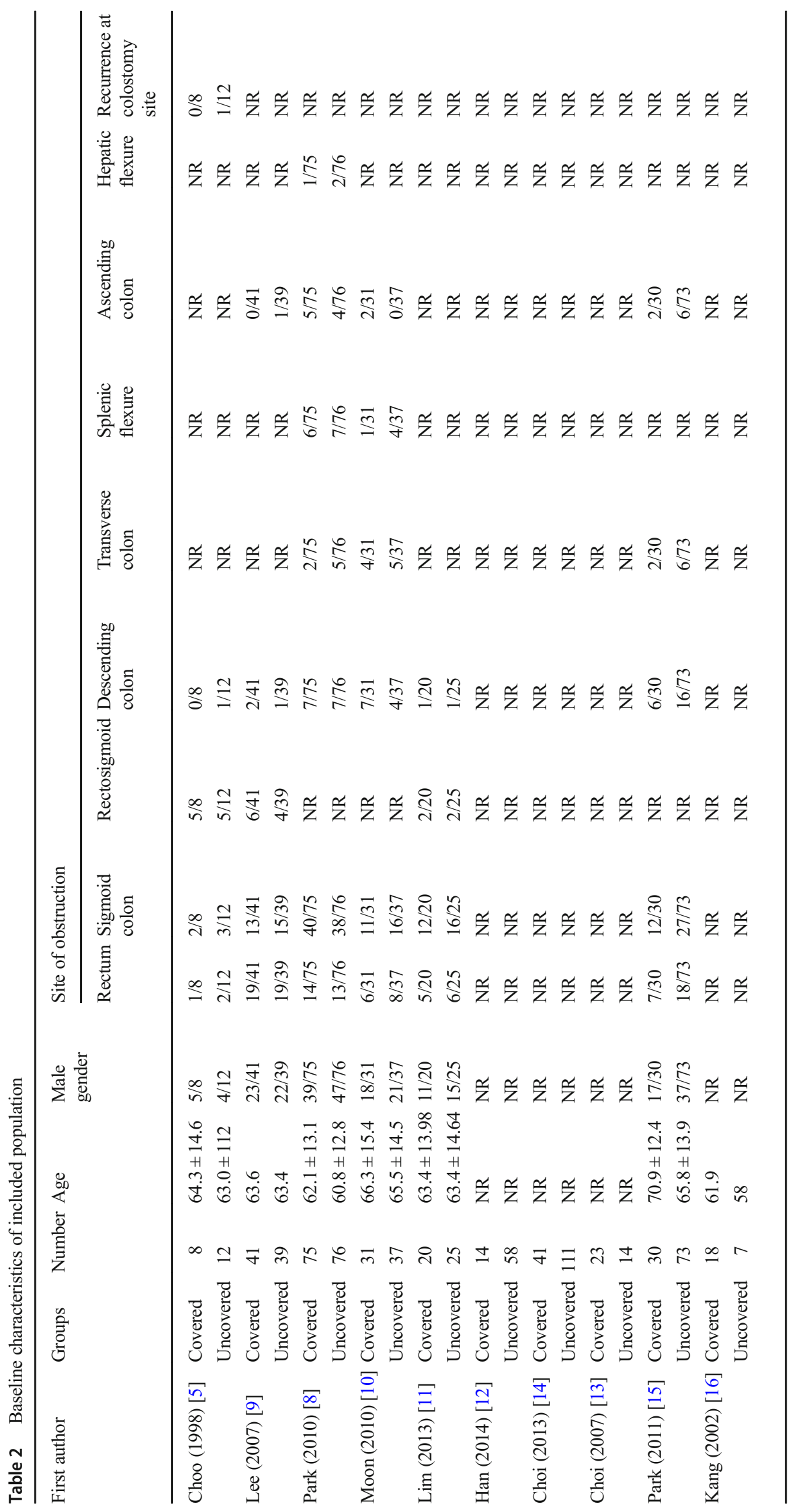



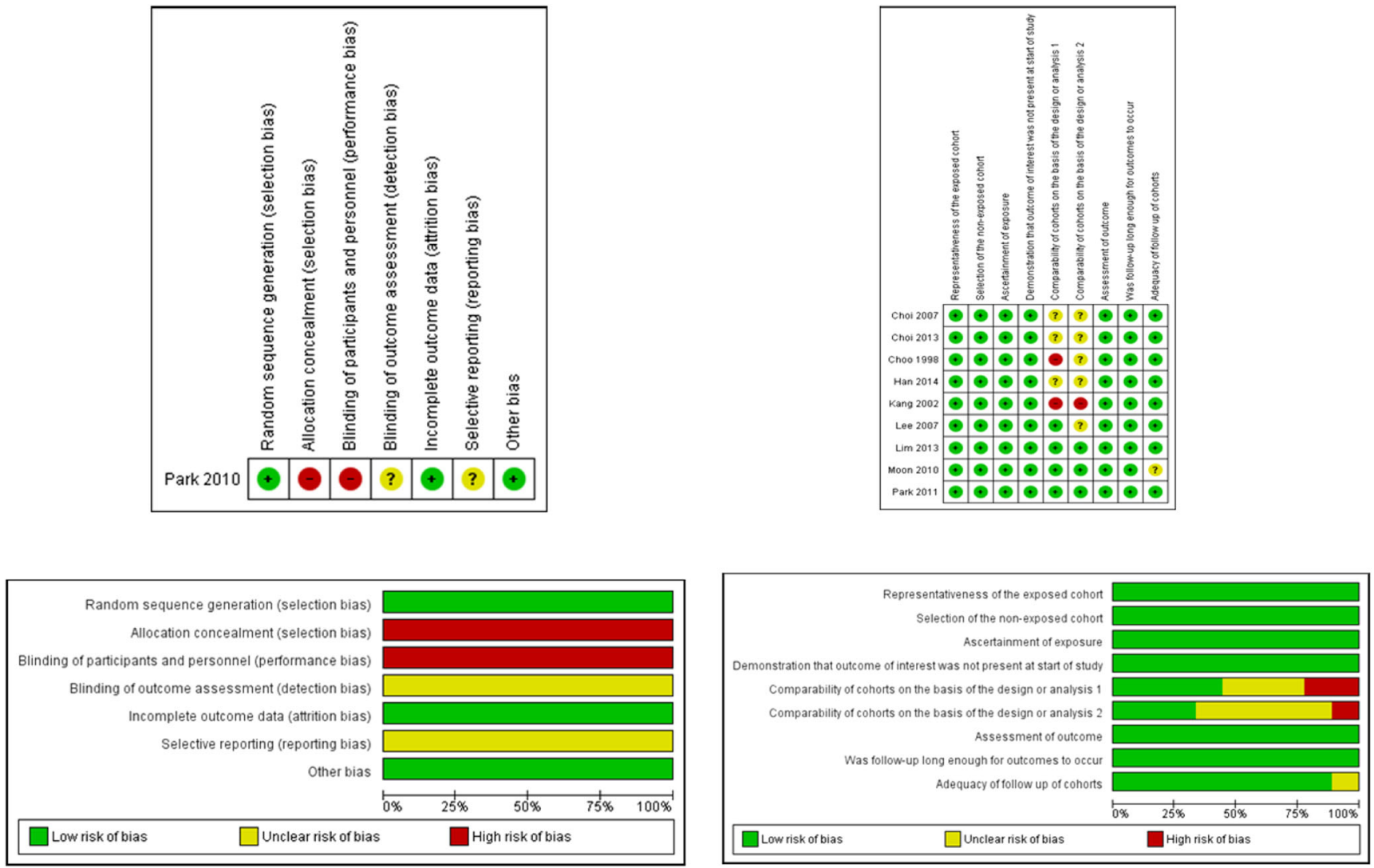

Fig. 2 Risk of bias summary and graph showing authors' judgements about each risk of bias item. a Randomised trial. b Observational studies

significant difference in clinical success of stent insertion (RR $1.0395 \%$ CI $0.98-1.08, P=0.32)$. A low level of inter-study heterogeneity existed $\left(I^{2}=0 \%, P=0.41\right)$ (Fig. 3 ).

Complications Total complications were reported in 9 studies [5, 8-11, 13-16], enrolling 681 patients. Risk of complications was lower in the uncovered stent group (RR $0.5795 \%$ CI $0.44-0.74, P<0.0001)$. A moderate level of inter-study heterogeneity existed $\left(I^{2}=50 \%, P=0.04\right)$ (Fig. 3 ).

Early complications Early complications were reported in 4 studies [5, 8-10], enrolling 319 patients. There was no significant difference in the risk of early complications (RR 0.54 95\% CI 0.25-1.16, $P=0.11)$. A moderate level of inter-study heterogeneity existed $\left(I^{2}=51 \%, P=0.11\right)$ (Fig. 3).

Late complications Late complications were reported in 3 studies [8-10], enrolling 299 patients. Risk of late complications was lower in the uncovered stent group (RR $0.5895 \%$ CI $0.34-0.99, P=0.05)$. A low level of inter-study heterogeneity existed $\left(I^{2}=0 \%, P=0.65\right)$ (Fig. 3).

Perforation Perforation was reported in 7 studies [8-11, 13, $15,16]$, enrolling 509 patients. There was no significant difference in the risk of perforation (RD $0.0195 \% \mathrm{CI}-0.03$ to
$0.02, P=0.65)$. A low level of inter-study heterogeneity existed $\left(I^{2}=0 \%, P=0.94\right)$ (Fig. 3).

Bleeding Bleeding was reported in 4 studies [8-11], enrolling 344 patients. There was no significant difference in the risk of bleeding (RD $0.0095 \% \mathrm{CI}-0.03$ to $0.03, P=0.98$ ). A low level of inter-study heterogeneity existed $\left(I^{2}=0 \%, P=0.80\right)$ (Fig. 3).

Stent migration Stent migration was reported in 9 studies [5, 8-13, 15, 16], enrolling 601 patients. The risk of stent migration was lower in the uncovered stent group (RR $0.2995 \% \mathrm{CI}$ $0.17-0.48, P<0.00001)$. A low level of inter-study heterogeneity existed $\left(I^{2}=33 \%, P=0.15\right)$ (Fig. 3$)$.

Early stent migration Early stent migration was reported in 6 studies [5, 8-10, 13, 16], enrolling 381 patients. There was no significant difference in the risk of early stent migration between the two groups (RR $0.4795 \%$ CI $0.21-1.06, P=0.07$ ). A low level of inter-study heterogeneity existed $\left(I^{2}=33 \%\right.$, $P=0.019$ ) (Fig. 3).

Late stent migration Late stent migration was reported in 5 studies [8-10, 13, 16], enrolling 361 patients. Risk of late stent migration was lower in the uncovered stent group (RR 
$0.1295 \%$ CI $0.04-0.37, P=0.0002)$. A low level of interstudy heterogeneity existed $\left(I^{2}=0 \%, P=0.90\right)$ (Fig. 3$)$.

Tumour ingrowth Tumour ingrowth was reported in 7 studies $[5,8-10,13,15,16]$, enrolling 484 patients. Risk of tumour ingrowth was higher in the uncovered stent group (RR 4.53 95\% CI 1.92-10.69, $P=0.0008)$. A low level of inter-study heterogeneity existed $\left(I^{2}=0 \%, P=0.62\right)$ (Fig. 3 ).

Tumour overgrowth Tumour overgrowth was reported in 6 studies [5, 8-10, 15, 16], enrolling 447 patients. The risk of tumour overgrowth was lower in the uncovered stent group (RR $0.2995 \%$ CI $0.09-0.93, P=0.04$ ). A low level of interstudy heterogeneity existed $\left(I^{2}=0 \%, P=0.99\right)$ (Fig. 3$)$.

Stool impaction Stool impaction was reported in 4 studies [8-10, 13], enrolling 336 patients. There was no significant difference in the risk of stool impaction (RR $0.5695 \% \mathrm{CI}$ $0.12-2.04, P=0.38)$. A low level of inter-study heterogeneity existed $\left(I^{2}=0 \%, P=0.47\right)$ (Fig. 3$)$.

Stent obstruction Stent obstruction was reported in 4 studies $[8,10,12,15]$, enrolling 334 patients. There was no significant difference in the risk of stent obstruction (RR $2.2395 \%$ CI 0.94-5.34, $P=0.97)$. A low level of inter-study heterogeneity existed $\left(I^{2}=0 \%, P=0.58\right)($ Fig. 3$)$.

Duration of stent patency Duration of stent patency was reported in 5 studies [8, 9, 13, 15, 16], enrolling 396 patients. Stents were patent for a significantly longer in the uncovered stent group (MD 18.47 95\% CI 10.46-26.48, $P<0.00001$ ). A low level of inter-study heterogeneity existed $\left(I^{2}=24 \%\right.$, $P=0.28)$ (Fig. 3).

Need for stent reinsertion Need for stent reinsertion was reported in 5 studies [5, 8-10, 13], enrolling 356 patients. There was a significantly lower need for stent reinsertion in the uncovered stent group (RR $0.3895 \%$ CI $0.17-0.86, P=0.02$ ). A low level of inter-study heterogeneity existed $\left(I^{2}=0 \%\right.$, $P=0.74)$ (Fig. 3).

\section{Additional analyses}

\section{Sensitivity analyses}

We performed sensitivity analyses for outcomes that were reported by at least four studies (all outcomes except late complications). The use of random-effects or fixed-effect models did not affect the direction of the effect sizes in any outcome measures. When ORs, RRs or RDs were calculated separately, the direction of the effect sizes remained unchanged for all the outcomes. Removing one study at a time changed the direction of the effect size in favour of uncovered stent for early
Fig. 3 Forest plots of the comparisons of outcomes between the uncovered and covered stent groups. a Technical success. b Clinical success. c Total complications. d Early complications. e Late complications. f Perforation. g Bleeding. h Stent migration (total). i Early stent migration. $\mathbf{j}$ Late stent migration. $\mathbf{k}$ Tumour ingrowth. $\mathbf{I}$ Tumour overgrowth. m Stool impaction. n Stent obstruction. o Stent patency duration. $\mathbf{p}$ Need for stent reinsertion

stent migration and early complications and changed it towards non-significance for tumour overgrowth and need for stent reinsertion; the direction of the effect sizes for other outcomes remained unchanged. The separate analyses for studies with low or moderate risk of bias did not affect the direction of the effect sizes.

\section{Subgroup analysis}

Data from the included studies was not adequate to perform subgroup analysis according to purpose for stenting (preoperative decompression vs palliative) or type of covered stent in terms (fully or partially covered). Hence, subgroup analysis was performed on shape of the stent.

Cylindrical-shaped stent Subgroup analysis of data from 276 patients showed that uncovered stents were associated with lower risks of total complications (RR $0.4895 \%$ CI 0.30 $0.75, P=0.002$ ), stent migration (RR $0.1095 \%$ CI $0.03-$ 1.30, $P<0.0001$ ), and need for stent reinsertion (RR 0.28 95\% CI $0.10-0.75, P=0.01)$ but higher risk of tumour ingrowth (RR $3.5695 \%$ CI 1.33-9.49, $P=0.01$ ) compared to cylindrical-shaped covered stents. There was no difference between the two groups in terms of technical success (RR $1.0295 \%$ CI $0.98-1.06, P=0.37$ ), clinical success (RR 1.00 95\% CI 0.93-1.08, $P=0.96$ ), perforation (RD $0.0195 \% \mathrm{CI}-$ 0.02-0.04, $P=0.64$ ), bleeding (RD $0.0195 \% \mathrm{CI}-0.02-0.04$, $P=0.58$ ), tumour overgrowth (RR $0.2895 \%$ CI $0.06-1.36$, $P=0.12$ ), stool impaction (RR $0.7995 \%$ CI $0.18-3.54, P=$ 0.76), stent obstruction (RR $1.8195 \%$ CI $0.60-5.43, P=$ 0.29 ), and duration of stent patency (MD 6.21 95\% CI 12.23-24.65, $P=0.51)$.

Dumbbell-shaped stent Subgroup analysis of data from 208 patients showed that uncovered stents were associated with longer duration of stent patency (MD $21.3295 \% \mathrm{CI}-12.43$ to $30.22, P<0.00001)$ and higher risk of tumour ingrowth (RR $7.5995 \%$ CI $1.30-44.25, P=0.02$ ) compared to dumbbellshaped covered stents. There was no difference between the two groups in terms of technical success (RR $1.0295 \% \mathrm{CI}$ 0.97-1.07, $P=0.39$ ), clinical success (RR $1.0695 \%$ CI 0.99 $1.13, P=0.07$ ), total complications (RR $0.9595 \%$ CI 0.62 $1.46, P=0.81$ ), perforation (RD $-0.0395 \% \mathrm{CI}-0.08$ to 0.03 , $P=0.33$ ), bleeding (RD $-0.0295 \% \mathrm{CI}-0.10$ to $0.05, P=$ 0.53 ), stent migration (RR $0.6295 \%$ CI $0.31-1.24, P=0.18$ ), 
a) Technical success

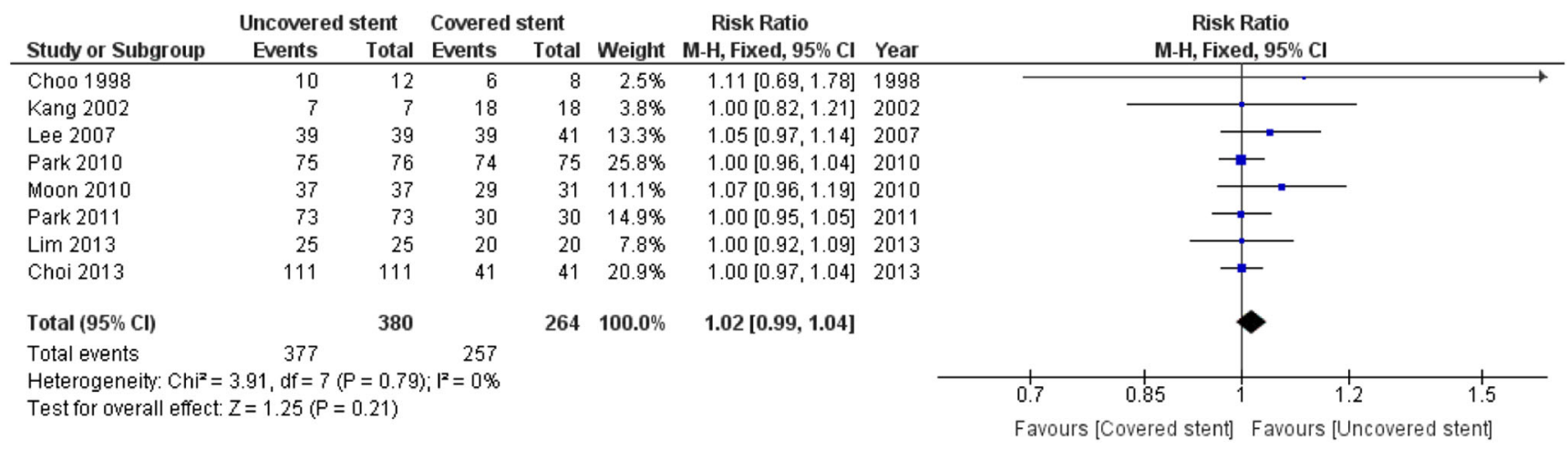

\section{b) Clinical success}

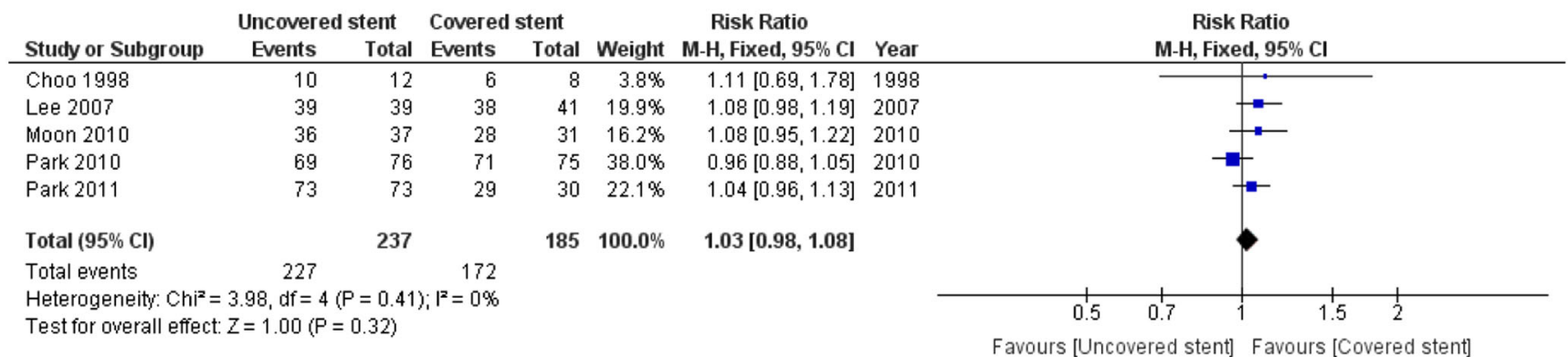

\section{c) Total complications}

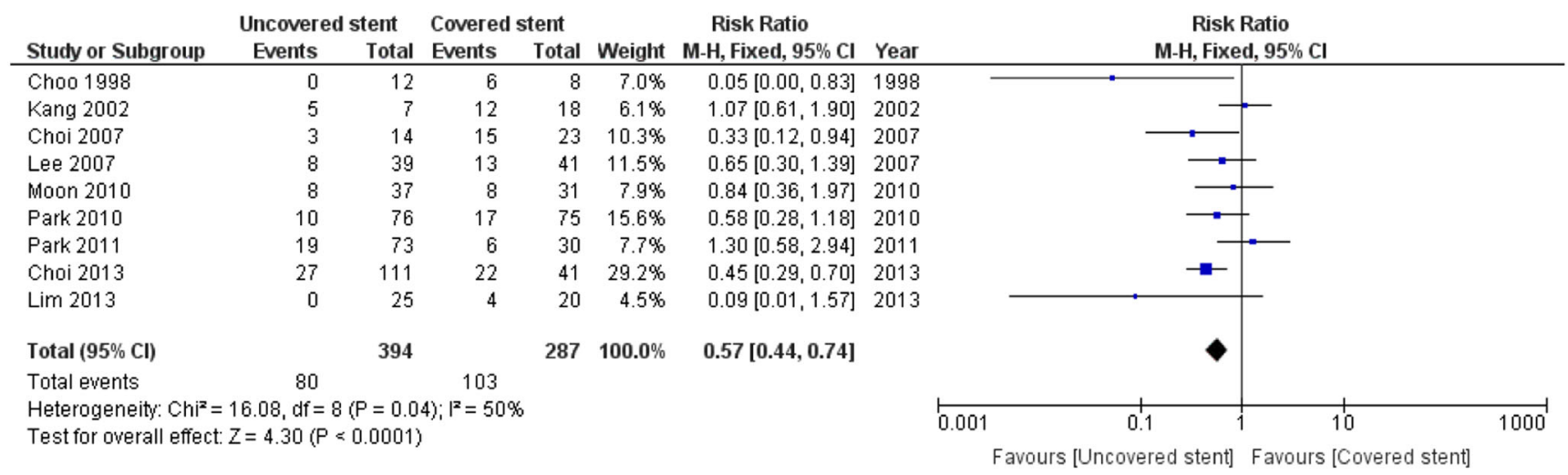

\section{d) Early complications}

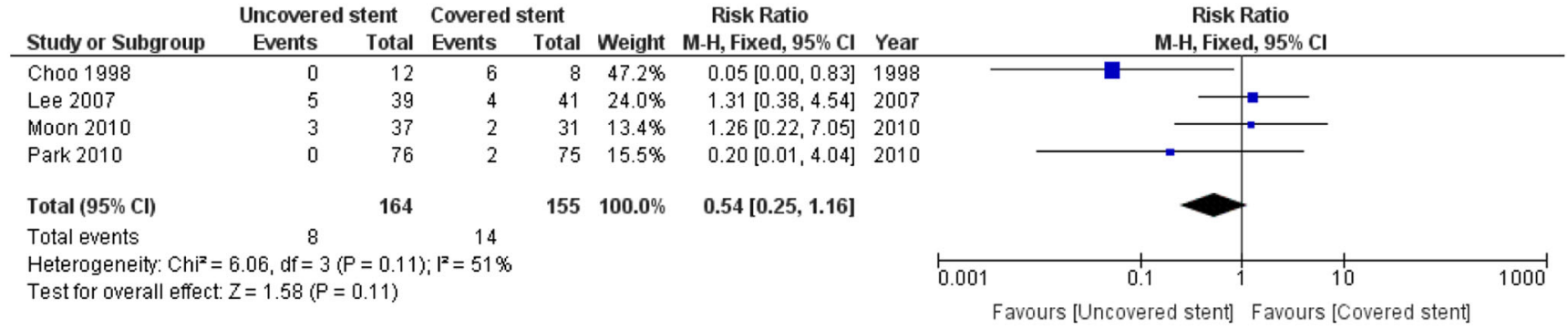




\section{e) Late complications}

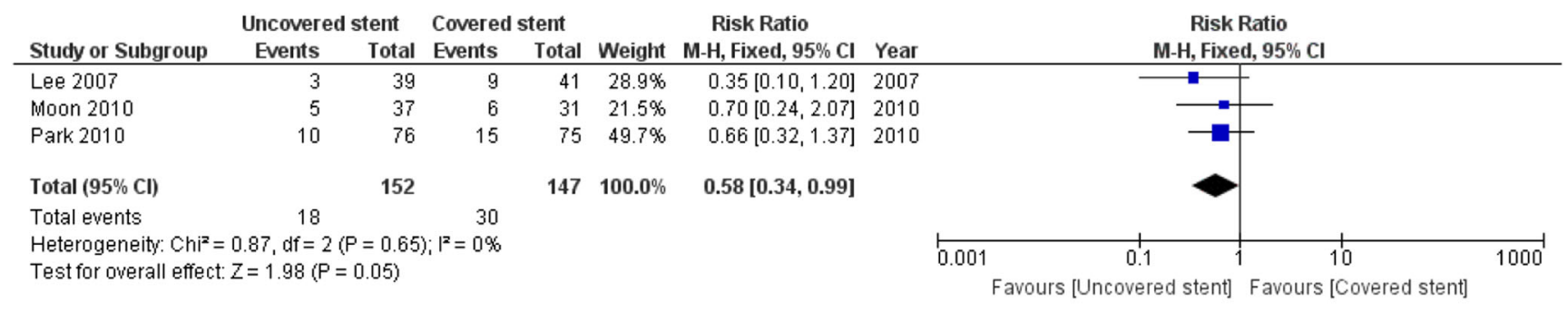

\section{f) Perforation}

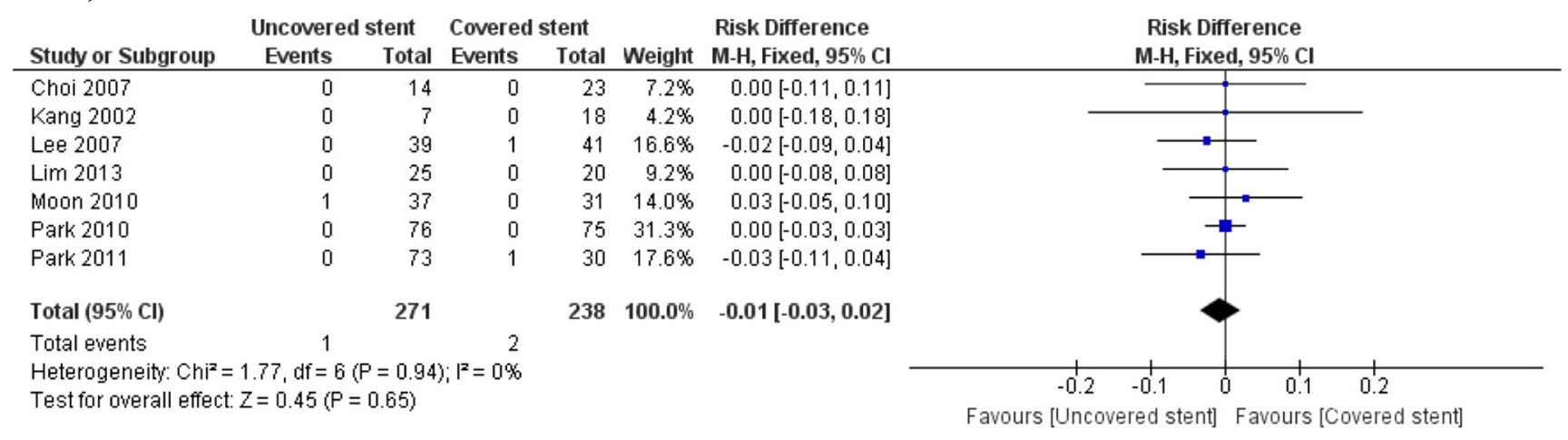

\section{g) Bleeding}

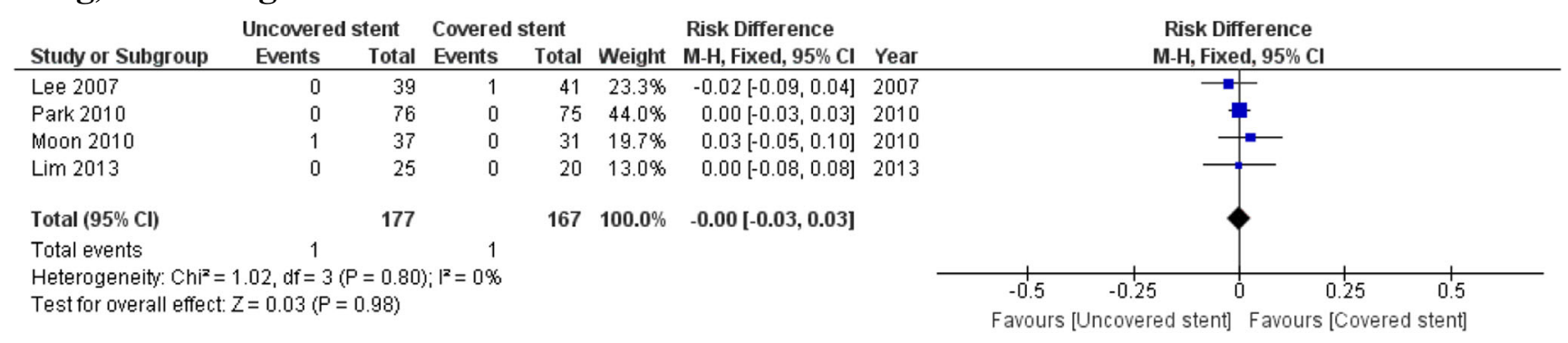

\section{h) Stent migration (total)}

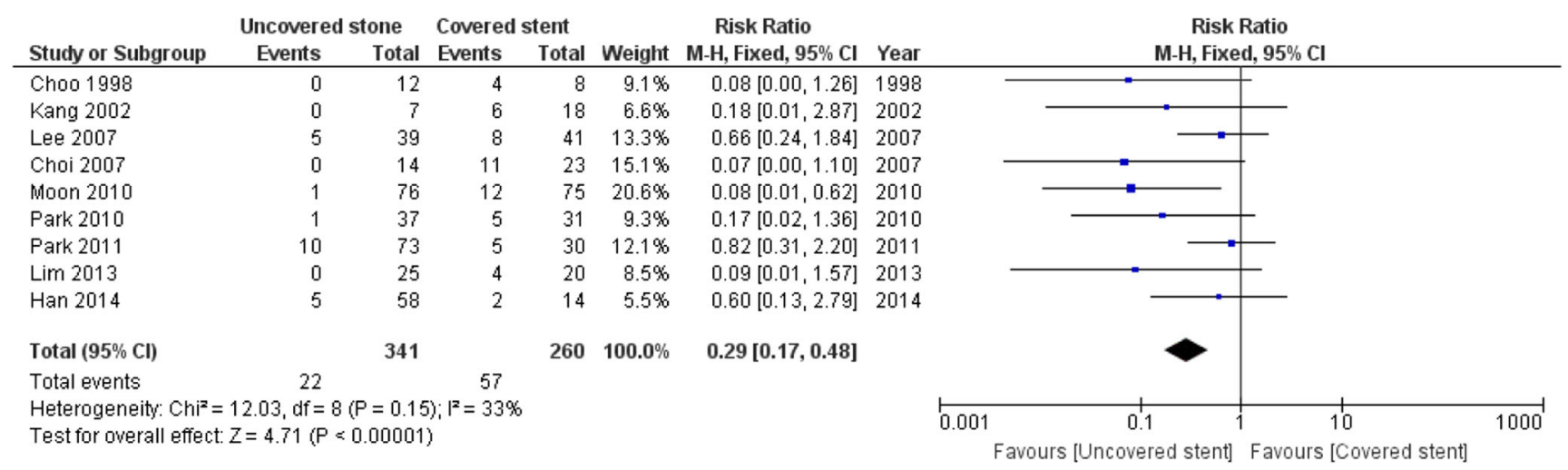

Fig. 3 continued.

tumour overgrowth (RR $0.3095 \%$ CI $0.05-1.67, P=0.17$ ), stool impaction (RR $0.2195 \%$ CI $0.01-4.24, P=0.31$ ), stent obstruction (RR $3.7095 \%$ CI 0.49-27.93, $P=0.20$ ), and need for stent reinsertion (RR $1.0595 \%$ CI $0.14-7.87, P=0.96$ ). 


\section{i) Early stent migration}

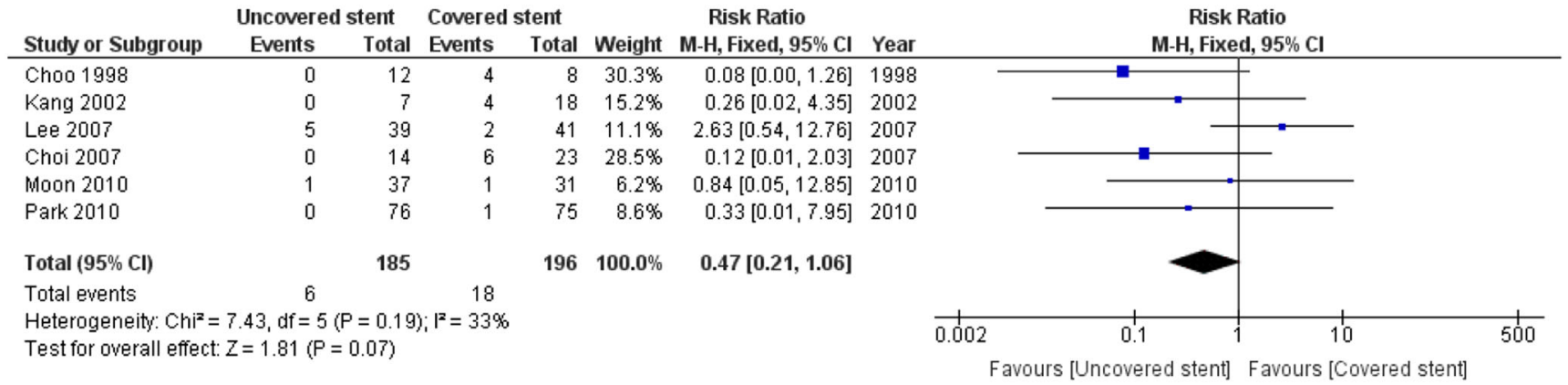

\section{j) Late stent migration}

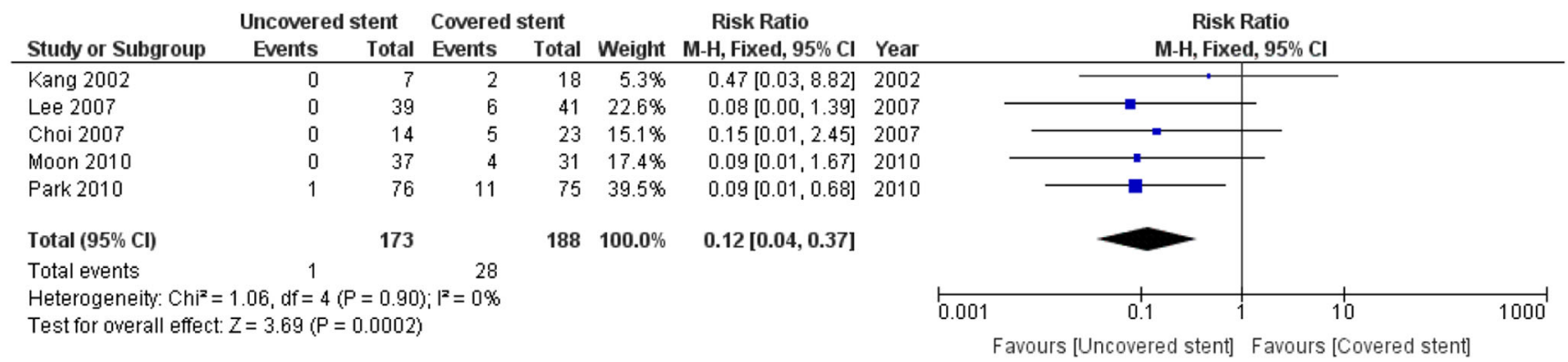

\section{k) Tumour ingrowth}

\begin{tabular}{|c|c|c|c|c|c|c|}
\hline \multirow[b]{2}{*}{ Study or Subgroup } & \multicolumn{2}{|c|}{ Uncovered stent } & \multicolumn{2}{|c|}{ Covered stent } & \multicolumn{2}{|r|}{ Risk Ratio } \\
\hline & Events & Total & Events & Total & Weight & M-H, Fixed, 95\% Cl \\
\hline Choo 1998 & 0 & 12 & 1 & 8 & $28.6 \%$ & $0.23[0.01,5.05]$ \\
\hline Kang 2002 & 1 & 7 & 0 & 18 & $4.8 \%$ & $7.13[0.32,156.93]$ \\
\hline Choi 2007 & 3 & 14 & 0 & 23 & $6.2 \%$ & $11.20[0.62,201.95]$ \\
\hline Lee 2007 & 3 & 39 & 0 & 41 & $7.9 \%$ & $7.35[0.39,137.84]$ \\
\hline Moon 2010 & 4 & 37 & 0 & 31 & $8.8 \%$ & $7.58[0.42,135.51]$ \\
\hline Park 2010 & 8 & 76 & 2 & 75 & $32.5 \%$ & $3.95[0.87,17.98]$ \\
\hline Park 2011 & 9 & 73 & 0 & 30 & $11.4 \%$ & $7.96[0.48,132.57]$ \\
\hline Total $(95 \% \mathrm{Cl})$ & & 258 & & 226 & $100.0 \%$ & $4.53[1.92,10.69]$ \\
\hline Total events & 28 & & 3 & & & \\
\hline $\begin{array}{l}\text { Heterogeneity: } \mathrm{Chi}^{2} \\
\text { Test for overall effec }\end{array}$ & $\begin{array}{l}45, d f=6 \\
=3.45(P\end{array}$ & 0.6 & & & & \\
\hline
\end{tabular}

\section{l) Tumour overgrowth}

\begin{tabular}{|c|c|c|c|c|c|c|}
\hline \multirow[b]{2}{*}{ Study or Subgroup } & \multicolumn{2}{|c|}{ Uncovered stent } & \multicolumn{2}{|c|}{ Covered stent } & \multirow[b]{2}{*}{ Weight } & \multirow{2}{*}{$\begin{array}{c}\text { Risk Ratio } \\
\text { M-H, Fixed, 95\% Cl }\end{array}$} \\
\hline & Events & Total & Events & Total & & \\
\hline Choo 1998 & 0 & 12 & 1 & 8 & $15.4 \%$ & $0.23[0.01,5.05]$ \\
\hline Kang 2002 & 0 & 7 & 2 & 18 & $12.9 \%$ & $0.47[0.03,8.82]$ \\
\hline Lee 2007 & 0 & 39 & 1 & 41 & $12.7 \%$ & $0.35[0.01,8.34]$ \\
\hline Park 2010 & 0 & 76 & 2 & 75 & $21.8 \%$ & $0.20[0.01,4.04]$ \\
\hline Moon 2010 & 1 & 37 & 2 & 31 & $18.9 \%$ & $0.42[0.04,4.40]$ \\
\hline Park 2011 & 0 & 73 & 1 & 30 & $18.3 \%$ & $0.14[0.01,3.33]$ \\
\hline Total $(95 \% \mathrm{Cl})$ & & 244 & & 203 & $100.0 \%$ & $0.29[0.09,0.93]$ \\
\hline Total events & 1 & & 9 & & & \\
\hline
\end{tabular}

Fig. 3 continued. 


\section{m) Stool impaction}

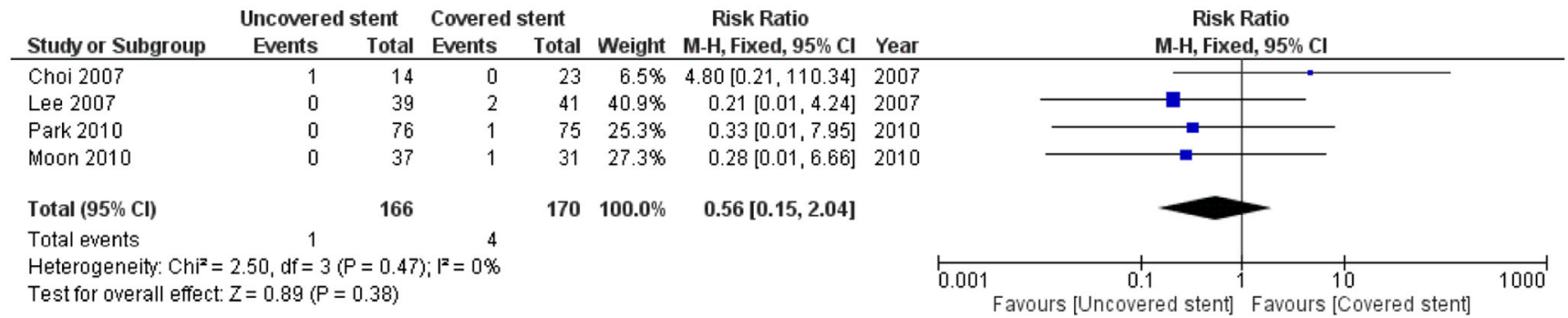

\section{n) Stent obstruction}

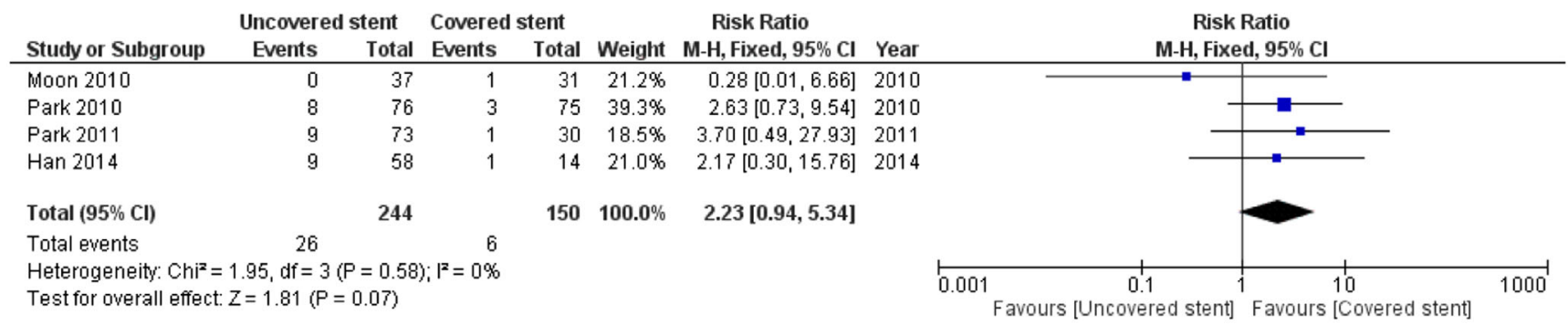

\section{o) Stent patency duration}

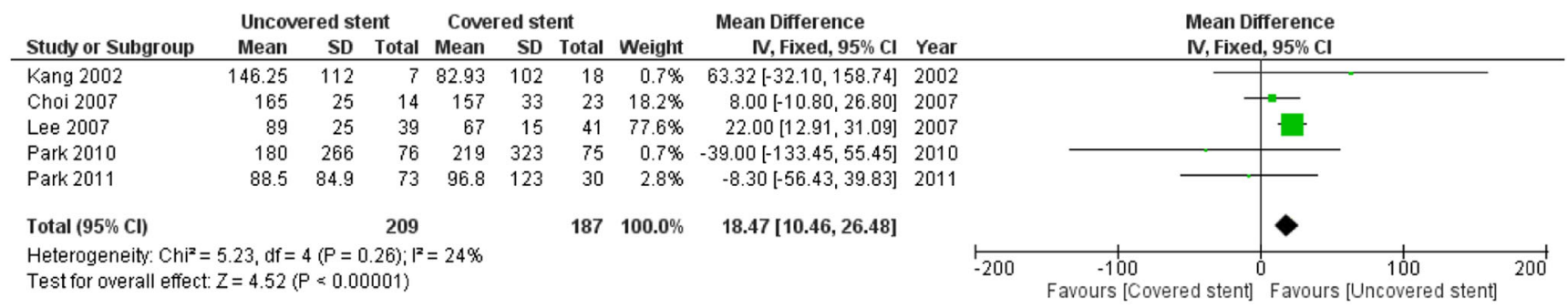

\section{p) Need for stent reinsertion}

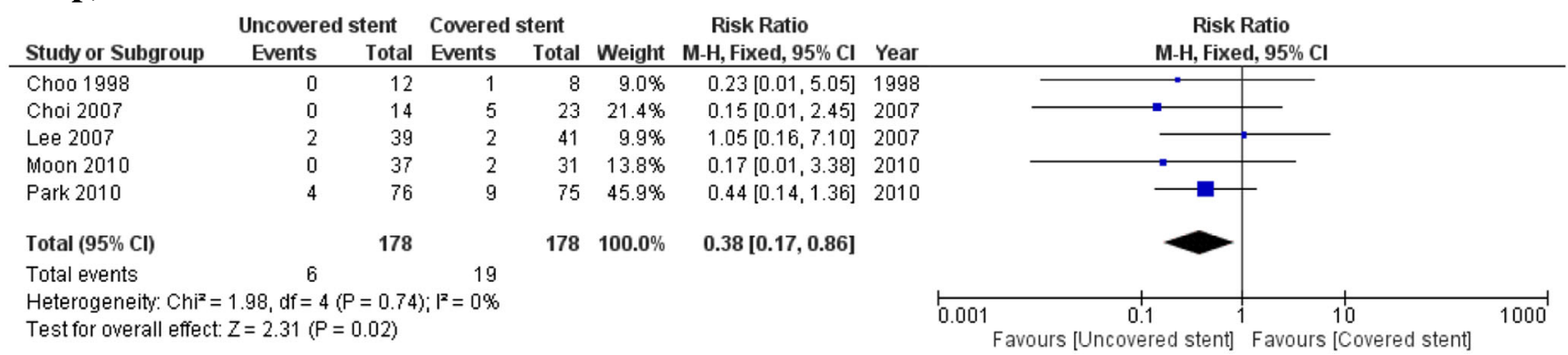

Fig. 3 continued.

\section{Discussion}

We performed a systematic review and meta-analysis comparing outcomes of covered versus uncovered stents in management of large bowel obstruction secondary to colonic malignancy, either primary or due to metastasis. Nine observational studies and one randomised controlled trial were included, totalling 753 patients. Analysis indicated insertion of uncovered stents was associated with lower risks of complications, tumour overgrowth, and stent migration: a lower need for stent reinsertion and a longer duration of patency. Covered stents were associated with a lower risk of tumour ingrowth. We found no significant difference in terms of technical success, clinical success, perforation, bleeding, stool impaction and stent obstruction. Between-study heterogeneity was low for all the outcomes except complications where the level of heterogeneity was 
moderate. The results remained consistent through sensitivity analyses. The quality of the evidence was moderate.

Our results indicate covered and uncovered stent insertion are equally feasible, indicated by comparable technical or clinical success rates. Presence of a stent covering should not significantly affect procedure of stent insertion. Whether the stent is covered or uncovered, it should not affect the procedure of stent insertion significantly. Difficulties in stent insertion are largely due to the characteristics of the lesion, such as a high-grade obstruction or the anatomy of the colon, such as tortuosity [17]. The sites of obstruction by tumour were comparable between the uncovered and covered stent groups in included studies. All of these may explain the comparable technical or clinical success rates in the uncovered stent and covered stent groups in our study.

Safety of stent insertion [18] was supported by early complication data; perforation was only seen in three cases and bleeding in two. Stent obstruction is the most common complication, mostly due to tumour ingrowth. Tumour ingrowth is narrowing of the stent lumen within interstices whilst tumour overgrowth is narrowing of the lumen at both ends of the stent by tumour growth [19]. The covering on an enteral stent is hypothetically supposed to decrease the risk of tumour ingrowth, given the mesh acts as a physical barrier in addition to the wire mesh. This largely explains the decreased rates of tumour ingrowth in the covered stent group found in this review. However, the presence of the mesh additionally impedes strong anchoring of the covered stent, as it cannot embed as firmly into the intestinal wall as compared to the wire mesh [20]. Hence, there is an increased risk of stent migration. New designs of covered stents such as partial covering, interior membranes, flanged ends or different shaped have been created to decrease stent migration $[9,21]$. Our pooled analysis demonstrated increased rates of overall and late stent migration in the covered stent group. Rates of early stent migration did not vary and perhaps this reflects insufficient time for the uncovered stent to embed in the intestinal wall. Further study could evaluate whether variation in stent design could contribute to decreasing the rates of stent migration.

Stent reinsertion [17] appears to be more effective than other techniques to relieve obstruction from stent migration, such as dilation, argon beamer or laser. Hence, rates of stent reinsertion were raised in the covered stent group, likely secondary to the increased rate of stent migration.

Risk of tumour overgrowth was significantly lower in the uncovered stent group. However, through sensitivity analyses, the direction of the effect size for tumour overgrowth moved towards non-significant; therefore, results for this outcome are not statistically robust. No included studies give details regarding patients who developed tumour overgrowth. The higher tumour overgrowth in the covered stent group may simply reflect the extent of disease in those individual patients.
Drug eluting, stents have been popularised in coronary intervention for their anti-tumour effects and are being investigated for enteral stent insertion [22]. Their potential for obstruction in colorectal malignancy has not been investigated, but perhaps this may further alleviate the problem of tumour ingrowth.

Our results indicated uncovered stents lasted 18 days longer despite the increased rate of tumour ingrowth, which may be due to the higher rate of stent migration in the covered group. Some argue covered stents are poorer when used for palliative purposes given the necessity for long-term patency, indicating a need for treatment stratification based on the purpose for stenting [20]. Unfortunately, data from the included studies did not allow subgroup analysis on this indication.

Our review and reported outcomes have limitations. We identified only 10 eligible studies of which 9 were nonrandomised observational studies that are inevitably subject to selection bias. Hence data does not provide robust basis for conclusions. The data from the included studies was not adequate to perform subgroup analysis based on the purpose for stenting (preoperative decompression vs palliative) or type of covered stent in terms of being fully or partially covered. Less than ten studies were eligible for this review, preventing formal assessment of publication bias as planned in our protocol; therefore, reporting bias cannot be excluded in this study.

\section{Conclusions}

The best available evidence suggests that uncovered stents are superior to covered stents in the management of large bowel obstruction due to colorectal malignancy as indicated by fewer complications, lower rates of stent migration, longer duration of patency and a reduced need for stent reinsertion. However, conclusions are largely from non-randomised studies. More randomised controlled trials are needed, especially stratifying by patient population (palliative vs bridge to surgery) and stent design (covered vs partially covered).

\section{Author contributions Project lead: SH \\ Conception and design: $\mathrm{SH}$ \\ Data collection: All authors \\ Analysis and interpretation: All authors \\ Writing the article: All authors \\ Critical revision of the article: All authors \\ Final approval of the article: All authors \\ Statistical analysis: $\mathrm{SH}$}

\section{Compliance with ethical standards}

Conflict of interest The authors declare that they have no conflict of interest.

Ethical approval Not required. 


\section{Appendix}

\begin{tabular}{ll}
\hline Search no. & Search strategy $^{\dagger}$ \\
\hline$\# 1$ & large bowel obstruction: TI, AB, KW \\
$\# 2$ & MeSH descriptor: [intestinal obstruction] explode all trees \\
$\# 3$ & MeSH descriptor: [colorectal cancer] explode all trees \\
$\# 4$ & $\# 1$ OR \#2 OR \#3 \\
$\# 5$ & MeSH descriptor: [stent] explode all trees \\
$\# 6$ & cover* near2 stent*: TI,AB,KW \\
$\# 7$ & uncover* near2 stent*: TI,AB,KW \\
$\# 8$ & Metal near 2 stent: TI,AB,KW \\
$\# 9$ & $\# 5$ OR \#6 OR \#7 OR \#8 \\
$\# 10$ & $\# 4$ AND \#9 \\
\hline
\end{tabular}

$\dagger$ This search strategy was adopted for following databases: MEDLINE, EMBASE, CINAHL and the Cochrane Central Register of Controlled Trials (CENTRAL)

Open Access This article is distributed under the terms of the Creative Commons Attribution 4.0 International License (http:// creativecommons.org/licenses/by/4.0/), which permits unrestricted use, distribution, and reproduction in any medium, provided you give appropriate credit to the original author(s) and the source, provide a link to the Creative Commons license, and indicate if changes were made.

\section{References}

1. Ripamonti C (Apr. 1994) Management of bowel obstruction in advanced cancer patients. J Pain Symptom Manag 9(3):193-200

2. Öhman U (Jun. 1982) Prognosis in patients with obstructing colorectal carcinoma. Am J Surg 143(6):742-747

3. Leitman IM, Sullivan JD, Brams D, DeCosse JJ (Jun. 1992) Multivariate analysis of morbidity and mortality from the initial surgical management of obstructing carcinoma of the colon. Surg Gynecol Obstet 174(6):513-518

4. Tilney HS, Lovegrove RE, Purkayastha S, Sains PS, WestonPetrides GK, Darzi AW, Tekkis PP, Heriot AG (Feb. 2007) Comparison of colonic stenting and open surgery for malignant large bowel obstruction. Surg Endosc 21(2):225-233

5. Choo IW, Do YS, Suh SW, Chun HK, Choo SW, Park HS, Kang SK, Kim SK (Feb. 1998) Malignant colorectal obstruction: treatment with a flexible covered stent. Radiology 206(2):415-421

6. Tack J, Gevers AM, Rutgeerts P (Sep. 1998) Self-expandable metallic stents in the palliation of rectosigmoidal carcinoma: a followup study. Gastrointest Endosc 48(3):267-271

7. Kim EJ, Kim YJ (Jan. 2016) Stents for colorectal obstruction: past, present, and future. World J Gastroenterol 22(2):842-852

8. Park S, Cheon JH, Park JJ, Moon CM, Hong SP, Lee SK, Kim TI, Kim WH (Aug. 2010) Comparison of efficacies between stents for malignant colorectal obstruction: a randomized, prospective study. Gastrointest Endosc 72(2):304-310
9. Lee KM, Shin SJ, Hwang JC, Cheong JY, Yoo BM, Lee KJ, Hahm KB, Kim JH, Cho SW (Nov. 2007) Comparison of uncovered stent with covered stent for treatment of malignant colorectal obstruction. Gastrointest Endosc 66(5):931-936

10. Moon CM, Kim TI, Lee MS, Ko BM, Kim HS, Lee KM, Byeon JS, Kim YS (Aug. 2010) Comparison of a newly designed doublelayered combination covered stent and D-weave uncovered stent for decompression of obstructive colorectal cancer: a prospective multicenter study. Dis Colon Rectum 53(8):1190-1196

11. Lim SG, Lee KJ, Suh† KW, Oh† SY, Kim SS, Yoo JH, Wi JO (May 2013) Preoperative colonoscopy for detection of synchronous neoplasms after insertion of self-expandable metal stents in occlusive colorectal Cancer: comparison of covered and uncovered stents. Gut Liver 7(3):311-316

12. Han JP, Hong SJ, Kim SH, Choi JH, Jung HJ, Cho YH, Ko BM, Lee MS (Aug. 2014) Palliative self-expandable metal stents for acute malignant colorectal obstruction: clinical outcomes and risk factors for complications. Scand J Gastroenterol 49(8):967-973

13. Choi JS, Choo SW, Park KB, Shin SW, Yoo SY, Kim JH, Do YS (2007) Interventional management of malignant colorectal obstruction: use of covered and uncovered stents. Korean J Radiol 8(1):5763

14. Choi JH, Lee YJ, Kim ES, Choi JH, Cho KB, Park KS, Jang BK, Chung WJ, Hwang JS (Sep. 2013) Covered self-expandable metal stents are more associated with complications in the management of malignant colorectal obstruction. Surg Endosc 27(9):3220-3227

15. Park JK, Lee MS, Ko BM, Kim HK, Kim YJ, Choi HJ, Hong SJ, Ryu CB, Moon JH, Kim JO, Cho JY, Lee JS (Apr. 2011) Outcome of palliative self-expanding metal stent placement in malignant colorectal obstruction according to stent type and manufacturer. Surg Endosc 25(4):1293-1299

16. Kang S-G, Jung GS, Cho SG, Kim JG, Oh JH, Song HY, Kim ES (2002) The efficacy of metallic stent placement in the treatment of colorectal obstruction. Korean J Radiol 3(2):79-86

17. Keymling M (Mar. 2003) Colorectal stenting. Endoscopy 35(3): 234-238

18. Khot UP, Lang AW, Murali K, Parker MC (Sep. 2002) Systematic review of the efficacy and safety of colorectal stents. Br J Surg 89(9):1096-1102

19. Moon S-H, Kim MH, Park DH, Song TJ, Eum J, Lee SS, Seo DW, Lee SK (Jul. 2010) Modified fully covered self-expandable metal stents with antimigration features for benign pancreatic-duct strictures in advanced chronic pancreatitis, with a focus on the safety profile and reducing migration. Gastrointest Endosc 72(1):86-91

20. Shin SJ, Kim TI, Kim BC, Lee YC, Song SY, Kim WH (May 2008) Clinical application of self-expandable metallic stent for treatment of colorectal obstruction caused by extrinsic invasive tumors. Dis Colon Rectum 51(5):578-583

21. Mauro MA, Koehler RE, Baron TH (Jun. 2000) Advances in gastrointestinal intervention: the treatment of gastroduodenal and colorectal obstructions with metallic stents. Radiology 215(3):659669

22. Song TJ, Lee SS, Yun SC, Park DH, Seo DW, Lee SK, Kim MH (Apr. 2011) Paclitaxel-eluting covered metal stents versus covered metal stents for distal malignant biliary obstruction: a prospective comparative pilot study. Gastrointest Endosc 73(4):727-733

Publisher's note Springer Nature remains neutral with regard to jurisdictional claims in published maps and institutional affiliations. 